\title{
Concordance of 24- and 48-h diagnostic follow-up ascitic fluid polymorphonuclear leukocyte count in the guidance of the antibiotic therapy in spontaneous bacterial peritonitis
}

Hanaa Mostafa Badran ${ }^{1}$, Maha Mohammad Elsabaawy ${ }^{1 *}$ (D, Mohamed Azazy Mahmoud², Heba Samy Ghanem³, Ayman Alsebaey ${ }^{1}$ and Warda Othman ${ }^{1}$

\begin{abstract}
Background: Spontaneous bacterial peritonitis (SBP) is an ascitic fluid infection in patients with liver cirrhosis in the absence of surgical causes. The drop of the ascitic fluid polymorphonuclear leukocyte count (AFPC) $\geq 25 \%$ of baseline $48 \mathrm{~h}$ post-start of antibiotics is a predictor of antibiotic response. This study was designed to compare the diagnostic accuracy of AFPC 24h of antibiotic to the standard 48h. Three hundred ninety-nine SBP patients were classified into 2 groups. Group I (31.1\%) are patients that lacked $\geq 25 \%$ drop and group II (68.9\%) the opposite.

Results: The average age was $51.99 \pm 11.21$ years. Most patients were males (70.9\%), normotensive (75.8\%), nondiabetics (50.8\%), and without recent intake history of proton pump inhibitors (75.8\%) and B-blockers (77\%). Group II patients had statistically significant $(p<0.05)$ serum sodium $129(7)$ vs. $128(8)$ and history of diabetes mellitus $60.3 \%$ vs. $39.7 \%$. The baseline AFPC did not differ statistically between groups I and II ( $p>0.05$ ). Group II patients compared to group I had statistically ( $p=0.001)$ lower AFPC 24h [800 (970) vs. 1100 (1700) cell//mm $\mathrm{mm}^{3}$, higher percent drop of the AFPC 24h [28.09 (24) vs. -10.17 (35)], and $\geq 25 \%$ drop [154 (90.6\%) vs. 16 (9.4\%)]. The 24h AFPC $>980 \mathrm{cell} / \mathrm{mm}^{3}$ was associated with AFPC 48h non-response (AUROC $=0.634, p=0.001,58.87 \%$ sensitivity, $64.36 \%$ specificity). The 24-h AFPC percent drop $>8 \%$ was associated with AFPC 48h response (AUROC $=0.849, p=0.001$, $85.82 \%$ sensitivity, $80.49 \%$ specificity).
\end{abstract}

Conclusion: Concordance of 24- and 48-h diagnostic follow-up ascitic fluid polymorphonuclear leukocyte count in the guidance of the antibiotic therapy.

Keywords: Spontaneous bacterial peritonitis, Ascites, Polymorphonuclear leukocyte count, Antibiotics

\footnotetext{
* Correspondence: maha.ahmed@liver.menofia.edu.eg

'Department of Hepatology and Gastroenterology, National Liver Institute,

Menoufia University, Shebeen El-Koom, Egypt

Full list of author information is available at the end of the article
}

\section{Springer Open}

(c) The Author(s). 2021 Open Access This article is licensed under a Creative Commons Attribution 4.0 International License, which permits use, sharing, adaptation, distribution and reproduction in any medium or format, as long as you give appropriate credit to the original author(s) and the source, provide a link to the Creative Commons licence, and indicate if changes were made. The images or other third party material in this article are included in the article's Creative Commons licence, unless indicated otherwise in a credit line to the material. If material is not included in the article's Creative Commons licence and your intended use is not permitted by statutory regulation or exceeds the permitted use, you will need to obtain permission directly from the copyright holder. To view a copy of this licence, visit http://creativecommons.org/licenses/by/4.0/. 


\section{Key points}

- SBP is a common complication in ascite patients.

- AFPC $48 \mathrm{~h}$ of the start of antibiotic therapy guides the therapy [ $\geq 25 \%$ drop].

- Etiology of SBP became different with increased incidence of multi-resistant bacteria and failure of therapy.

- Changing the time point of follow-up AFPC from 48 to $24 \mathrm{~h}$ may be more helpful in the guidance of treatment.

\section{Background}

Liver cirrhosis and portal hypertension may be complicated by ascites, esophageal varices, hepatorenal syndrome, and encephalopathy $[1,2]$. Within 10 years of cirrhosis diagnosis, $60 \%$ of the patients develop ascites [3].

Spontaneous bacterial peritonitis (SBP) is an ascitic fluid infection in patients with liver cirrhosis in the absence of surgical causes [4]. It develops in up to $30 \%$ of ascite patients [5] alone or in association with spontaneous bacterial empyema [6]. Cirrhosis-related immune dysfunction as decreased complement and opsonic activity, small intestinal bacterial overgrowth and bacterial translocation, systemic inflammatory response, and circulatory dysfunction, all are incriminated in SBP pathogenesis [5].

It might be asymptomatic, otherwise should be suspected in patients with liver cirrhosis presenting with abdominal pain, fever, ileus, acute kidney injury, and hepatic encephalopathy [3].

SBP is associated with poor prognosis and hospital mortality up to $10-50 \%$. Accordingly, patients with SBP should be listed for liver transplantation. Antibiotics as IV cefotaxime should be started immediately till culture results. After $48 \mathrm{~h}$ of antibiotic therapy, ascitic fluid polymorphonuclear leukocyte count (AFPC) should be taken. If AFPC decreases by $\geq 25 \%$ of baseline, continue the same antibiotic regimen. If not, change to another antibiotic till culture results [3].

This study aimed to compare diagnostic AFPC 24h after starting antibiotic to the standard time after $48 \mathrm{~h}$.

\section{Methods}

This observational hospital-based study was conducted at National Liver Institute Hospitals, Menoufia University, from June 2016 to June 2017. An informed written consent was obtained from all enrolled patients after prior institutional review board approval.

Three hundred ninety-nine (399) patients diagnosed to have SBP were included. SBP was defined as AFPC $\geq 250$ cell $/ \mathrm{mm}^{3}$ without obvious surgical cause [7].

The exclusion criteria were patients less than 18 years and patients with mixed or non-portal hypertensionrelated ascites as with tuberculosis or local malignancy, secondary peritonitis, and hepatocellular carcinoma. Also, patients with prior antibiotic intake and other sources of infection as otitis media and upper respiratory tract infection all were excluded.

On admission, all patients had underwent baseline ascitic fluid analysis for chemistry, liver function tests, kidney function tests, CBC, INR, and abdominal ultrasonography.

On the diagnosis, empirical cefotaxime $2 \mathrm{~g}$ IV/8h was started after taking bedside blood cultures. On 24 and $48 \mathrm{~h}$ of starting antibiotics, follow-up diagnostic AFPC were done. According to the 48 -h results, if the AFPC drop was $\geq 25 \%$ of the baseline value, continue to the same antibiotic therapy. If not change to another group, mostly levofloxacin $500 \mathrm{mg} \mathrm{IV} / 24$ or meropenem $0.5 \mathrm{~g}$ IV/8h till the culture results [3].

The endpoint of the study was at $48 \mathrm{~h}$ of treatment. Accordingly, patients were classified into two groups. Group I (31.1\%) are patients that lacked $\geq 25 \%$ drop of 48-h AFPC, defined as non-responders, and group II (68.9\%) with a fair reduction in 48-h AFPC (more than or equal to $25 \%$ of baseline readings).

Data was statistically analyzed using $\mathrm{IBM}^{\circ} \mathrm{SPSS}^{\circ}$ Statistics $^{\circ}$ version 21 for Windows (IBM Corporation, Armonk, NY, USA) and MedCalc ${ }^{\circ}$ version 18.2.1 (Seoul, Republic of Korea). Data are expressed as mean \pm standard deviation for normally distributed data, number with row percentage for nominal data, and the median \pm interquartile range for non-normally distributed data. All $p$ values are 2 -tailed, with values $<0.05$ considered statistically significant. Comparisons between the two groups were performed using Student's $t$ test for normally distributed data, the Mann-Whitney test for non-normally distributed data, and the chi-squared test $\left(\chi^{2}\right)$ and Fisher exact test for categorical data analysis. The receiver operating characteristic (ROC) curve analysis was used for the detection of the cutoff value. The area under ROC (AUROC) $<0.79$ is poorly discriminative.

\section{Results}

This study included 399 patients with SBP. The average age was $51.99 \pm 11.21$ years. Most patients were males (70.9\% with a ratio of 2.4:1 females), normotensive (75.8\%), non-diabetics (50.8\%), and without recent intake history of proton pump inhibitors (75.8\%) and B-blockers (77\%). Hepatitis $C$ virus was the etiology of cirrhosis in $79.5 \%$, and the rest was due to hepatitis B virus.

The clinical presentations of SBP were as follows: fever ( $n=187,46.75 \%)$, abdominal pain $(165,41.25 \%)$, upper gastrointestinal bleeding $(49,12.25 \%)$, hepatic encephalopathy $(89,22.5 \%)$, and hypotension $(66,16.5 \%)$. They are comparable statistically between groups I and II $(p>0.05)$. Only $10 \%$ of the patients had positive ascitic fluid culture, and $90 \%$ had negative culture. 
As shown in Table 1, both groups I and II were comparable $(p>0.05)$ as regards the age, sex, history of diabetes mellitus, proton pump inhibitors, B-blockers, liver function tests, $\mathrm{CBC}$, kidney functions, and the ChildPugh score.

Group II patients had statistically significant $(p<0.05)$ serum sodium $129 \pm 7$ vs. $128 \pm 8$ and history of diabetes mellitus $60.3 \%$ vs. $39.7 \%$.

The baseline AFPC did not differ statistically between groups I and II $(p>0.05)$. Group II patients compared to group I (Table 1, Fig. 1) had statistically ( $p=0.001$ ) lower AFPC 24h [800 (970) vs. 1100 (1700) cell/ $\left.\mathrm{mm}^{3}\right]$, higher percent drop of the AFPC 24h [28.09 (24) vs. -10.17 (35)], and $\geq 25 \%$ drop [154 (90.6\%) vs. 16 (9.4\%)].

On studying the change of AFPC from baseline to 24h post-start of antibiotics, $27.8 \%$ had increased count and $72 \%$ of the patients had decreased AFPC $(42.6 \% \geq 25 \%$ decreased AFPC and $29.6 \%$ were the rest).

Group II patients compared to group I (Fig. 2) had statistically $(p=0.001)$ lower percent of increased $24 \mathrm{~h}$

Table 1 Comparative demographic, clinical, and laboratory data of both groups

\begin{tabular}{|c|c|c|c|}
\hline & $\begin{array}{l}\text { Group I } \\
N=124(31.1 \%)\end{array}$ & $\begin{array}{l}\text { Group II } \\
N=275(68.9 \%)\end{array}$ & $p$ \\
\hline Age, years & $52.65 \pm 10.60$ & $51.57 \pm 11.82$ & 0.432 \\
\hline Males & 87 (30.7\%) & $196(69.3 \%)$ & 0.821 \\
\hline Hypertension & $18(25 \%)$ & $54(75 \%)$ & 0.163 \\
\hline Diabetes mellitus & $58(39.7 \%)$ & $88(60.3 \%)$ & 0.003 \\
\hline Proton pump inhibitors & $18(25 \%)$ & $54(75 \%)$ & 0.163 \\
\hline B-blockers & $22(32.4 \%)$ & $46(67.6 \%)$ & 0.904 \\
\hline Total bilirubin, mg/dL & $2.61 \pm 2.4$ & $2.40 \pm 3.6$ & 0.386 \\
\hline Albumin, g/dL & $2.46 \pm 0.49$ & $2.52 \pm 0.52$ & 0.237 \\
\hline AST, U/L & $89.30 \pm 72.62$ & $79.24 \pm 67.94$ & 0.181 \\
\hline$A L T, U / L$ & $53.04 \pm 40.65$ & $51.73 \pm 42.17$ & 0.772 \\
\hline Urea, mg/dL & $109.78 \pm 72.02$ & $102.94 \pm 78.10$ & 0.408 \\
\hline Creatinine, mg/dL & $1.88 \pm 1.51$ & $1.60 \pm 1.5$ & 0.065 \\
\hline Sodium, mmol/L & $128 \pm 8$ & $129 \pm 7$ & 0.030 \\
\hline Hemoglobin, g/dL & $10.10 \pm 2.75$ & $10.50 \pm 2.3$ & 0.597 \\
\hline WBCs, $\times 103 / \mu \mathrm{L}$ & $9.55 \pm 5.85$ & $9.20 \pm 5.6$ & 0.300 \\
\hline Platelets, $\times 103 / \mu \mathrm{L}$ & $101.50 \pm 55$ & $102.00 \pm 69$ & 0.955 \\
\hline CTP score & $9.7 \pm 2.5$ & $9.6 \pm 2.2$ & 0.630 \\
\hline AFPC baseline, cell $/ \mathrm{mm}^{3}$ & $975 \pm 1445$ & $1000 \pm 1380$ & 0.419 \\
\hline AFPC $24 \mathrm{~h}$, cell $/ \mathrm{mm}^{3}$ & $1100 \pm 1700$ & $800 \pm 970$ & 0.001 \\
\hline AFPC $24 \mathrm{~h}$ percent drop & $-10.17 \pm 35$ & $-28.09 \pm 24$ & 0.001 \\
\hline AFPC $24 h \geq 25 \%$ drop & $16(9.4 \%)$ & $154(90.6 \%)$ & 0.001 \\
\hline AFPC $48 \mathrm{~h}$, cell $/ \mathrm{mm}^{3}$ & $900 \pm 1590$ & $500 \pm 630$ & 0.001 \\
\hline
\end{tabular}

AFPC ascitic fluid polymorphonuclear leukocyte count, AST aspartate aminotransferase, ALT alanine aminotransferase, WBCS white blood cells, CTP Child-Pugh Score

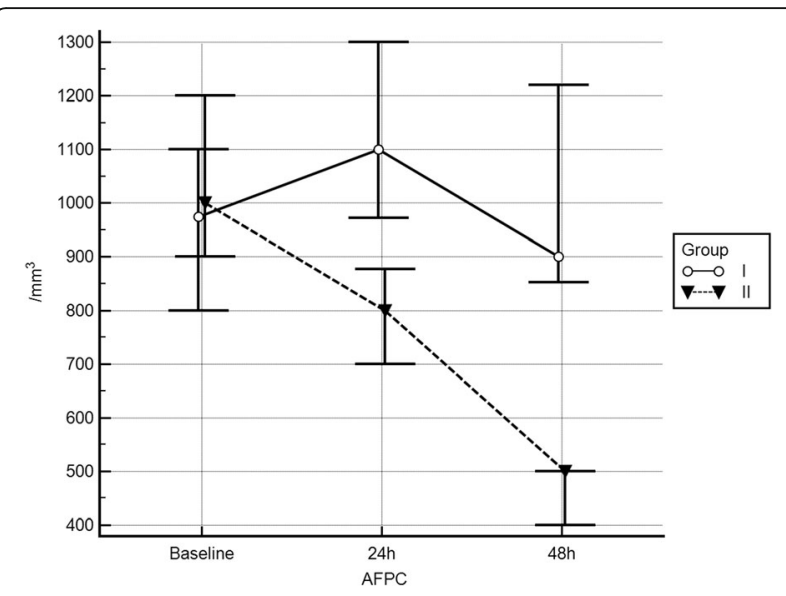

Fig. 1 Serial AFPC in both groups

AFPC [28 (25.2\%) vs. $83(74.8 \%)]$ and higher percent of $24 \mathrm{~h}$ AFPC drop $\geq 25 \%$ [154 (90.6\%) vs. 16 (9.4\%)].

The receiver operating characteristic curve analysis (Table 2, Fig. 3) revealed that 24-h AFPC $>980 \mathrm{cell} / \mathrm{mm}^{3}$ was associated with AFPC $48 \mathrm{~h}$ non-response (AUROC = $0.634, p=0.001,58.87 \%$ sensitivity, $64.36 \%$ specificity).

The 24-h AFPC percent drop $>8 \%$ was associated with AFPC $48 \mathrm{~h}$ response (AUROC $=0.849, p=0.001,85.82 \%$ sensitivity, $80.49 \%$ specificity). If the cutoff was changed $>25 \%$, the sensitivity decreased to $52.73 \%$ and specificity increased to $88.62 \%$. Statistically, the AFPC percent drop was better than the 24-h AFPC (AUROC 0.849 vs. 0.634, $p=0.001$ ).

\section{Discussion}

The development of SBP in patients with ascites is associated with a poor prognosis. It may be complicated with acute kidney injury and hepatorenal syndrome, so prophylactic albumin infusion is useful [3]. One of the main pillars in pathogenesis is bacterial translocation, so

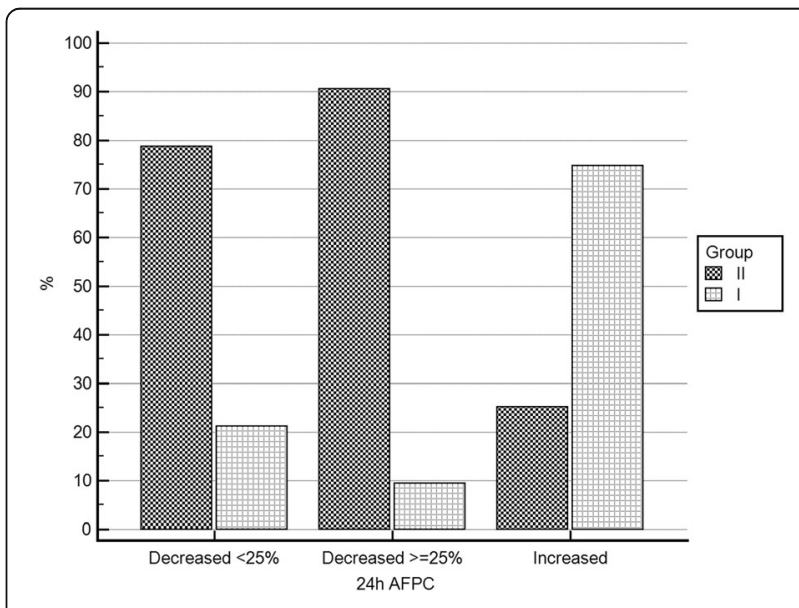

Fig. 2 Patterns of the 24-h AFPC in both groups 
Table 2 Relation between 24-h AFPC and type of treatment response in SBP patients

\begin{tabular}{|c|c|c|c|c|}
\hline \multirow[b]{2}{*}{ Cutoff } & \multirow{2}{*}{$\begin{array}{l}\text { 24-h AFPC and non-response } \\
>980 \mathrm{cell} / \mathrm{mm}^{3}\end{array}$} & \multicolumn{3}{|c|}{ 24-h AFPC percent drop and response } \\
\hline & & $>8 \%$ & $>980 \mathrm{cell} / \mathrm{mm}^{3}$ & $>8 \%$ \\
\hline AUROC & 0.634 & 0.849 & 0.634 & 0.849 \\
\hline$p$ value & 0.001 & 0.001 & 0.001 & 0.001 \\
\hline $95 \% \mathrm{Cl}$ & $0.584-0.681$ & $0.810-0.883$ & $0.584-0.681$ & $0.810-0.883$ \\
\hline Sensitivity & $58.87 \%$ & $85.82 \%$ & $58.87 \%$ & $85.82 \%$ \\
\hline Specificity & $64.36 \%$ & $80.49 \%$ & $64.36 \%$ & $80.49 \%$ \\
\hline PPV & $42.7 \%$ & $90.8 \%$ & $42.7 \%$ & $90.8 \%$ \\
\hline NPP & $77.6 \%$ & $71.7 \%$ & $77.6 \%$ & $71.7 \%$ \\
\hline
\end{tabular}

AFPC ascitic fluid polymorphonuclear leukocyte count, $A U R O C$ area under the receiver operating characteristic, $C l$ confidence interval, $P P V$ positive predictive value, NPV negative predictive value

proton pump inhibitors were accused of precipitating SBP [8] While early reports mentioned that B-blockers are protective of SBP [9], recent studies recommended strict monitoring or stopping them in patients with SBP [4].

The success of the antibiotic therapy can be suspected by improvement of the clinical condition and improving the abdominal pain (3). Being a subjective measurement for treatment judging, added to the fact that many patients are asymptomatic, so reliance on diagnostic follow-up 48-h AFPC of treatment was a good alternative to adjudicate the antibiotic therapy (3).

In 1986, Runyon and Hoefs [10] in a small number study ( $n=24)$ were the first to use AFPC to follow-up the response to antibiotics in SBP patients. In fact, they measured serial AFPC to try to differentiate primary from non-perforation secondary peritonitis. After the initiation of the antibiotics, the AFPC had decreased

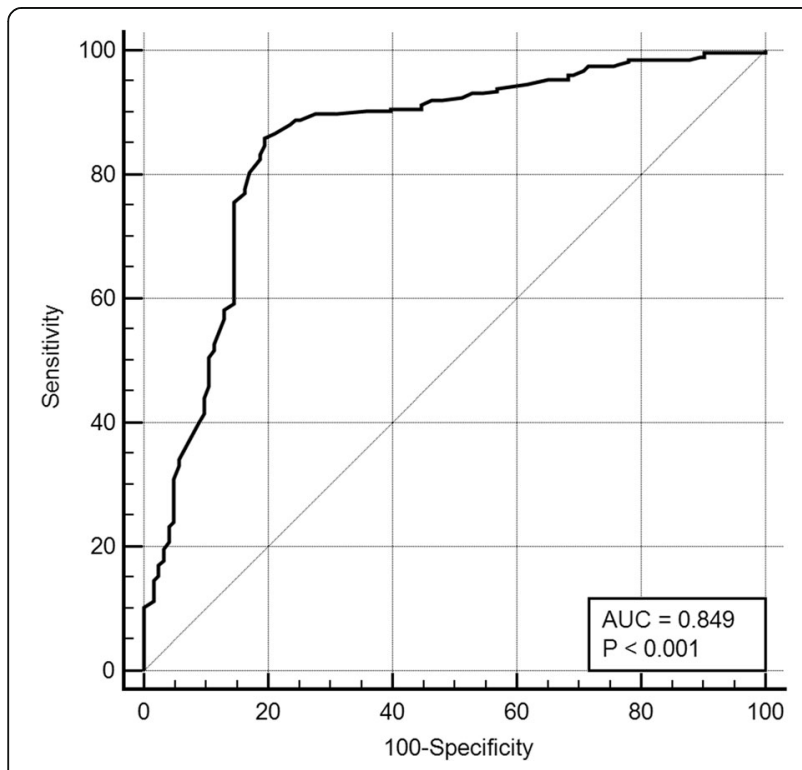

Fig. 3 The receiver operating characteristic curve of the 24-h AFPC percent drop exponentially. The total mean AFPC half-life $\left(t^{1} / 2\right)$ was 34 $\pm 35 \mathrm{~h}\left(t^{1} / 2\right.$ was $36 \pm 9 \mathrm{~h}$ for the survivors and $38 \pm 40 \mathrm{~h}$ for patients who died, $p>0.05$ ). Based on the $t^{1 / 2}$, the $48-\mathrm{h}$ follow-up AFPC was adopted. The SBP patients who survived had 48-h AFPC $<50 \%$ of the baseline.

In 1989, Fong et al. [11] in a small number study $(n=33)$ tried to validate 48 - $\mathrm{h}$ follow-up AFPC. The mean percent drop of AFPC was $92 \%$ in the survivors compared to $67 \%$ in the non-survivors $(p=0.001)$. The endpoint of treatment was AFPC $<250 \mathrm{cell} / \mathrm{mm}^{3}$.

In 2000, based on the above studies, the first consensus for the diagnosis and management of SBP [12] suggested that 48-h AFPC should be done and considered arbitrary a cutoff of $\geq 25 \%$ decrease to define response to antibiotics.

AASLD guidelines 2009 [7] suggested on-demand follow-up AFPC if suspecting non-response to therapy. In 2012, the AASLD guidelines [13] suggested follow-up AFPC with nosocomial setting, culture of atypical organism, or recent B-lactam antibiotic exposure. The British guidelines [14] did not mention the follow-up AFPC in its recommendations.

The EASL guidelines 2010 [3] suggested 48-h AFPC to guide the antibiotic therapy but did not mention the cutoff in the recommendations. The case is the same with the most recent one [4].

What is new in this study? In fact, knowledge is increasing and the advance in sciences urges revisions of definitions that were considered as a taboo. For example, the definition of cure from $\mathrm{HCV}$ by antivirals was defined for years by negative HCV RNA measured 24 weeks from end of antiviral treatment as seen in AASLD guidelines 2009 [15]. By the progression of knowledge, the duration was recently shortened to 12 weeks [16].

Do we really need to change the time of follow- up AFPC from 48 to $24 \mathrm{~h}$ ? In the past, SBP was diagnosed clinically and by diagnostic AFPC. Treatment was continued till improvement of the clinical symptoms only. This approach was problematic in patients with asymptomatic SBP, so follow-up AFPC approach adopted 
by Runyon and Hoefs [10] was very helpful. Few years ago, SBP was caused mainly by gram-negative bacteria, and some guidelines suggested on-demand follow-up 48-h AFPC [7, 13] and some recommended it [3, 4].

Nowadays, SBP may be of three types communityacquired, healthcare-associated, and nosocomial type. The latter 2 are caused by usually gram-positive bacteria and have an aggressive course especially if multi-drug resistant and may progress to sepsis. They have less response to conventional therapy and need strong antibiotic therapy from the start as carbapenem, vancomycin, or linezolid [4].

With the recent aggressive change of the SBP map, early prediction of antibiotic treatment failure is warranted to avoid progression to sepsis and ominous outcome. The second point that waiting till culture results may be not helpful in critical cases especially those with high baseline AFPC and immunosuppressed state where time saving is mandatory and a lot of cases the culture is negative. As a result, changing the time point of follow-up AFPC from 48 to $24 \mathrm{~h}$ may be helpful.

In the current study, 399 patients with SBP were included with a baseline AFPC that range was 250-12,000 cell $/ \mathrm{mm}^{3}$. Responders to antibiotics who had $\geq 25 \%$ decreased 48-h AFPC compared to non-responders, who had reported increased 24h AFPC.

We tried to have a cutoff predicting non-response to antibiotic therapy. The 24-h AFPC $>980 \mathrm{cell} / \mathrm{mm}^{3}$ was associated with AFPC $48 \mathrm{~h}$ non-response, but the AUROC is small and statistically poor. In contrast, the 24h AFNC percent drop $>8 \%$ was associated with AFPC $48 \mathrm{~h}$ response with statistically good AUROC $(0.849, p=$ $0.001,85.82 \%$ sensitivity, $80.49 \%$ specificity). On choosing another cutoff $(>25 \%)$, the sensitivity decreased (52.73\%), while the specificity increased (88.62\%).

\section{Conclusion}

Reliance on reduction in 24-h AFPC more than $8 \%$ as a prognostic test of treatment response in SBP patients might be of value rather than waiting for 48 -h readings. The saved costs of antibiotics and hospital stay, along with the reduction of patient sufferings, esteemed enough to change a settled prognostic concept.

The limitations of this study are the relatively low number of patients, single-center experience, and lack of longitudinal follow-up and the survival assessment.

\section{Abbreviations}

AFPC: Ascitic fluid polymorphonuclear leukocyte count; SBP: Spontaneous bacterial peritonitis; ROC: Receiver operating characteristic; AUROC: Area under ROC; Cl: Confidence interval; IQR: Interquartile range

\section{Acknowledgements}

This research is completely tendered to the noble soul of Dr. Mohamed Azazy, the one who oversaw the clinical contacts with the cases and was lost in the corona outbreak. May the most merciful forgive him and let him lie in peace till heavens.

\section{Authors' contributions}

$\mathrm{HB}$ initiated the project, designed and implemented the study for application, and was the team leader. ME and AA analyzed the data and drafted and revised the paper. MA contributed to the clinical evaluation for proper patient selection with clinical and laboratory follow-up. HG contributed to the biochemical and cellular analysis of blood and ascitic fluid samples and follow-up. WO contributed to the clinical follow-up along with overall evaluation and decisions and drafting the manuscript. All authors have read and approved the final manuscript. A poster from this abstract was presented at the Asian Pacific Association for the Study of the Liver 2018.

\section{Funding}

This research and the publication were completely funded by all authors.

\section{Availability of data and materials}

Data used to support the findings of this study are included within the article.

\section{Declarations}

Ethics approval and consent to participate

The study conformed to the ethical guidelines of the 1975 Declaration of Helsinki and was approved by the institutional review board of National Liver Institute (NLI IRB 00003413), Menoufia University, Egypt (approval no. 00119/ 2015). Written informed consents were obtained from all included patients.

\section{Consent for publication}

Written informed consents were obtained from all patients.

\section{Competing interests}

The authors declare that they have no competing interests.

\section{Author details}

${ }^{1}$ Department of Hepatology and Gastroenterology, National Liver Institute, Menoufia University, Shebeen El-Koom, Egypt. ²Alahrar Educational Hospital, Ministry of Health, Zagazig, Egypt. ${ }^{3}$ Department of Clinical Pathology, National Liver Institute, Menoufia University, Shebeen El-Koom, Egypt.

Received: 8 October 2020 Accepted: 6 April 2021

Published online: 27 April 2021

\section{References}

1. Elsabaawy MM, Abdelhamid SR, Alsebaey A, Abdelsamee E, Obada MA, Salman TA, Rewisha E (2015) The impact of paracentesis flow rate in patients with liver cirrhosis on the development of paracentesis induced circulatory dysfunction. Clin Mol Hepatol 21(4):365-371. https://doi.org/10.33 50/cmh.2015.21.4.365

2. Ibrahim ES, Alsebaey A, Zaghla H, Moawad Abdelmageed S, Gameel K, Abdelsameea $E$ (2017) Long-term rifaximin therapy as a primary prevention of hepatorenal syndrome. European Journal of Gastroenterology \& Hepatology 29(11):1247-1250. https://doi.org/10.1097/MEG. 0000000000000967

3. European Association for the Study of the Liver (2010) EASL clinical practice guidelines on the management of ascites, spontaneous bacterial peritonitis, and hepatorenal syndrome in cirrhosis. J Hepatol 53(3):397-417

4. Angeli P, Bernardi M, Villanueva C, Francoz C, Mookerjee RP, Trebicka J, Krag A, Laleman W, Gines P (2018) EASL Clinical Practice Guidelines for the management of patients with decompensated cirrhosis. Journal of Hepatology 69(2):406-460. https://doi.org/10.1016/j.jhep.2018.03.024

5. Lee JM, Han KH, Ahn SH (2009) Ascites and spontaneous bacterial peritonitis: an Asian perspective. Journal of Gastroenterology and Hepatology 24(9):1494-1503. https://doi.org/10.1111/j.1440-1746.2009. 06020.x

6. Mohamed A, Atef M, Alsebaey A, Musa Elhabshy M, Salama M (2017) Combined spontaneous bacterial empyema and peritonitis in cirrhotic patients with ascites and hepatic hydrothorax. Arab Journal of Gastroenterology 18(2):104-107. https://doi.org/10.1016/j.ajg.2017.05.010 
7. Runyon BA (2009) Management of adult patients with ascites due to cirrhosis: an update. Hepatology (Baltimore, Md.) 49(6):2087-2107

8. Bajaj JS, Zadvornova Y, Heuman DM, Hafeezullah M, Hoffmann RG, Sanyal AJ, Saeian K (2009) Association of proton pump inhibitor therapy with spontaneous bacterial peritonitis in cirrhotic patients with ascites. The American Journal Of Gastroenterology 104(5):1130-1134. https://doi.org/1 0.1038/ajg.2009.80

9. M. Senzolo, E. Cholongitas, P. Burra, G. Leandro, U. Thalheimer, D. Patch, A.K. Burroughs, $\beta$-Blockers protect against spontaneous bacterial peritonitis in cirrhotic patients: a meta-analysis, 29(8) (2009) 1189-1193.

10. Runyon BA, Hoefs JC (1986) Spontaneous vs secondary bacterial peritonitis. Differentiation by response of ascitic fluid neutrophil count to antimicrobial therapy. Archiv Int Med 146(8):1563-1565. https://doi.org/10.1001/a rchinte.146.8.1563

11. Fong TL, Akriviadis EA, Runyon BA, Reynolds TB (1989) Polymorphonuclear cell count response and duration of antibiotic therapy in spontaneous bacterial peritonitis. Hepatology (Baltimore, Md.) 9(3):423-426

12. Rimola A, Garcia-Tsao G, Navasa M, Piddock LJ, Planas R, Bernard B, Inadomi JM (2000) Diagnosis, treatment and prophylaxis of spontaneous bacterial peritonitis: a consensus document. Int Ascites Club J Hepatol 32(1):142-153. https://doi.org/10.1016/s0168-8278(00)80201-9

13. B.A. Runyon, Introduction to the revised American Association for the Study of Liver Diseases Practice Guideline management of adult patients with ascites due to cirrhosis 2012, 57(4) (2013) 1651-1653.

14. Moore KP, Aithal GP (2006) Guidelines on the management of ascites in cirrhosis. Gut 55(Suppl 6):vi1-v12

15. Ghany MG, Strader DB, Thomas DL, Seeff LB (2009) Diagnosis, management, and treatment of hepatitis C: an update. Hepatology (Baltimore, Md.) 49(4): 1335-1374

16. Hepatitis $C$ guidance: AASLD-IDSA recommendations for testing, managing, and treating adults infected with hepatitis C virus, 62(3) (2015) 932-954.

\section{Publisher's Note}

Springer Nature remains neutral with regard to jurisdictional claims in published maps and institutional affiliations.

\section{Submit your manuscript to a SpringerOpen ${ }^{\circ}$ journal and benefit from:}

- Convenient online submission

- Rigorous peer review

- Open access: articles freely available online

High visibility within the field

- Retaining the copyright to your article

Submit your next manuscript at $\boldsymbol{\nabla}$ springeropen.com 